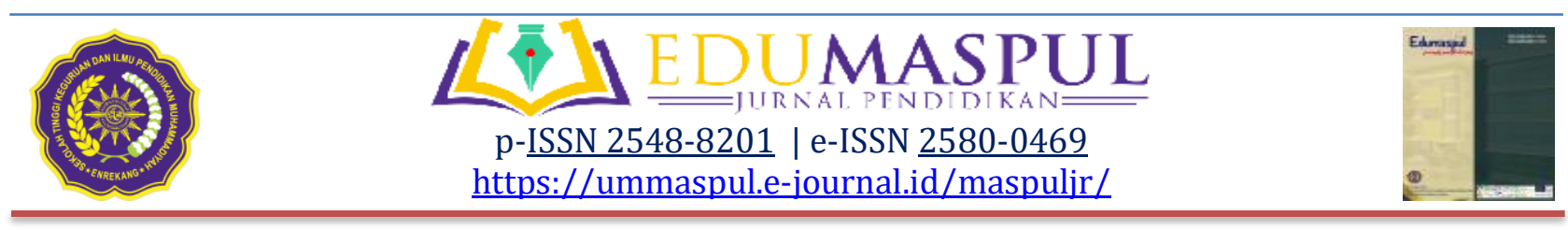

\title{
Literasi Digital di Kalangan Mahasiswa PGSD Universitas Muhamamdiyah Malang
}

\author{
Delora Jantung Amelia', Bahrul Ulumu²
}

1,2PGSD,FKIP, Universitas Muhammadiyah Malang, Indonesia

$\bowtie$ Corresponding email: 1delorajantung@umm.ac.id; ${ }^{2}$ ulumseo@gmail.com

\begin{abstract}
Receive: 25-09-2019
Accepted: 02-10-2019

Published: 08-10-2019

Abstrak: Penggunaan media social dikalangan mahasiswa bukanlah hal yang baru lagi. Kalangan mahasiswa atau lebih dikenal sebagai generasi milineal merupakan pengguna terbesar dalam dunia digital. Mahasiswa menggunakan media digital tidak hanya untuk mencari referensi sebagai bahan kuliah akan tetapi digunakan untuk beraneka ragam keperluan. Tujuan pada penelitian ini yaitu untuk mengetahui seberapa jauh mahasiswa dapat mengatahui dan memahami dunia digital dengan sebaik mungkin serta dapat menggunakan secara tepat guna. Temuan yang diperoleh oleh peneliti rata-rata mahasiswa sudah memahami dengan baik dunia digital akan tetapi masih belum semuanya dapat menggunakan sesuai dengan kebutuhan. Dari 180 mahasiswa yang dijadikan sampel penelitian sejumlah 114 berada dalam kategori medium dalam kemampuan literasi dunia digital.
\end{abstract}

Kata Kunci: literasi digital, mahasiswa

Abstract: The use of social media among students is nothing new. Among students or better known as the millennial generation is the largest user in the digital world. Students use digital media not only to look for references as lecture material but are used for various purposes. The purpose of this study is to find out how far students can know and understand the digital world as well as possible and can use it appropriately. The findings obtained by the average student researchers have a good understanding of the digital world but still not all of them can use as needed. Of the 180 students who were used as research samples a number of 114 were in the medium category in digital world literacy abilities.

Keywords: Digital literacy, students

\section{PENDAHULUAN}

Penggunaan media digital dikalangan remaja merupakan suatu hal yang tidak dapat dipisahkan lagi. Pengguna media social hampir $90 \%$ dikalangan mahasiswa terhubung dengan dunia digital facebook, instagram, whatsapp messeger, yang merupakan suatu hal yang tidak dapat dipisahkan lagi dengan kegiatan seharihari mahasiswa. Era digital memberikan kesempatan kepada mahasiswa untuk memperoleh informasi menjadi jauh lebih terbuka, maka pada titik itu makin terbukalah kesempatan mahasiswa untuk mengetahui informasi tentang dunia luar dan ajang memperkenalkan dirinya sendiri dikalangan yang lebih luas lagi. Di era yang seperti ini menguat di era digital seperti sekarang ini, literasi memiliki peran yang sangat strategis.

Literasi diera digital sangat berbeda sekali dengan literasi yang terbentuk di era industri sebelumnya. Pada dunia 
digital lebih mengarah kepada kegiatan komunikasi, menjalin relasi baik itu berupa relasi bisnis atau relasi berteman, berpikir, dan aktivitas lain yang berkaitan dengan media digital. Mengembangkan pengertian literasi digital ialah bagian dari upaya memahami bagaimana media memberikan dampak terhadap berbagai kegiatan yang berhubungan dengan literasi. Dengan kata lain, literasi digital pada dewasa ini tidak hanya sebagai ajang mencari informasi untuk mengerjakan tugas kuliah akan tetapi sebagai bentuk suatu kebutuhan yang sedikit sulit terpisahkan. Mahasiswa di era cyber ini gemar mengakses situs-situs informasi diinternet, mengakses games online sampai menggunakan social media dan aplikasi-aplikasi yang memudahkan pertemanan dalam gadget canggih miliknya. Kehidupan mahasiswa saat ini ibarat tidak eksis jika tidak memiliki dan menggunakan gadget, apalagi kebutuhahan tersebut telah beralih dari kebutuhan tersier menjadi kebutuhan primer.

Dengan kegiatan mahasiswa yang tidak terlepas dari dunia digital harus didukung dengan kemampuan pemahaman literasi digital yang baik. Kemampuan literasi digital yang kurang baik akan berdampak pada psikologis mahasiswa yang akan cenderung menghina orang lain, menimbulkan sifat iri, mengakibatkan depresi, terkadang terbawa arus suasana hati serta komentar negative kepada apa yang dilihat dan dibuka pada media digital. Dengan masuknya mahasiswa pada dunia digital matakuliah media sangat bagus diberikan kepada mahasiswa semester awal. Buchingham, (2001) berpendapat bahwa pendidikan media bertujuan untuk mengembangkan pemahaman kritis maupun partisipasi aktif sehingga dapat membuat para anak muda (mahasiswa) berfikir sesuai dengan apa yang dilihat dan sesuai dengan informasi.

Berdasarkan hasil pengamatan terhadap mahasiswa PGSDdalam setiap kesempatan, untuk berkomunikasi suara maupun komunikasi data. Tingginya penggunaan media digital ini harus diimbangi pula dengan pemahaman yang baik akan fungsi media tersebut. Dengan demikian maka pengetahuan mengenai critical understandingliterasi media digital menjadi kemampuan yang harus dimiliki mahasiswa. Hal ini diperlukan agar mahasiswa memiliki kesiapan mental dalam menghadapi berbagai tantangan di era revolusi industry 4.0 ini. Generasi muda sebagai elemen masyarakat harus selalu hadir untuk bersikap kritis terhadap setiap perubahan yang terjadi, dimana sikap kritis ini sebagi sebuah keharusan demi menjaga bangsa dan negara ini dari proxy war.

Kuriniawati dan Bororoh, 2016 mengatakan pengertian literasi media terdiri dari dua kata yakni literasi dan media. Literasi dapat dikatakan sebagai kemampuan membca dan menulis sedangkan media merupakan suatu perantara dalam wujud benda manusia, suatu peristiwa. Dengan kata lain literasi digital dapat dipaparkan sebagai bentuk mahasiswa untuk mencari dan memanfaatkan berbagai media digital dalam berbagai keperluan dan kegiatan. Stevany, 2017 mengungkapkan bahwa literasi media merupakan suatu bentuk kemampuan seseorang dalam menggunakan media social yang dilakukan secara kritis dan kreatif dalam menfilter segala informasi yang beredar diberbagai media.

\section{METODE}

Pada penelitian ini menggunakan penelitian deskriptif kualitatif, yaitu 
penelitian yang bermaksud membuat (deskripsi) mengenai situasi-situasi atau kejadian-kejadian. Tujuan utama dari penelitan pendidikan ialah untuk menguji dan menggambarkan individu, kelompok, situasi dan yang menggambarkan literasi media digital PGSD UMM. Metode penelitian menggunakan metode survey. Pengumpulan data pada penelitian ini dilakukan dengan teknik kuisoner, dokumentasi. Kuisoner dilakukan untuk mengetahui literasi digital mahasiswa PGSD Universitas Muhamamdiyah Malang. Untuk mengumpulkan data, penelitian ini menggunakan instrumen yang berupa : kuisoner dan dokumentasi

Analisis data dilakukan secara deskriptif baik secara kualitatif maupun kuantitatif. Sebagaimana pada umumnya analisis data secara kualitatif dilakukan dengan reduksi data, penafsiran/pemaknaan,dan penyimpulan hasil analisis. Data mengenai literasi media digital dilakukan dengan beberapa cara observasi, wawancara, dokumentasi, kemudian ditulis ulang, dipaparkan apa adanya, kemudian dipilah-pilahsesuai fokus penelitian, setelah melalui proses analisis dalam kerangka memperoleh data yang sahih dengan member chek, triangulasi, dan pelacakan mendalam, kemudian disimpulkan dan dimaknai.

\section{HASIL DAN PEMBAHASAN}

\section{Kemampuan Literasi Media Digital Mahasiswa}

Berdasarkan hasil jawaban dari mahasiswa Pendidikan guru Sekolah Dasar khsusunya angkatan 2018 dapat dipaparkan hasil kemampuan literasi media digital melalui pertanyaan terkait kemampuan literasi digital media Adapun pertanyaan dan hasil jawaban mahasiswa yang berjumlah 180 antara lain dari kriteria critical understanding terdiri dari Kemampuan memahami konten dan fungsi media, pengetahuan tentang media dan regulasi media dan perilaku pengguna dalam menggunakan media.

1. Bagaimana cara anda memahami informasi yang anda peroleh dari media digital?

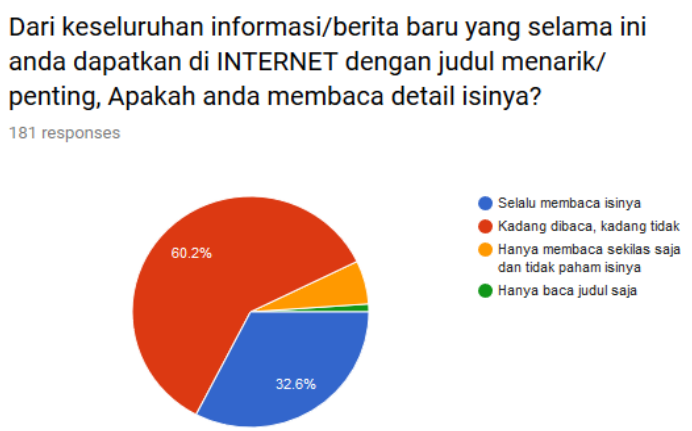

Dari data diatas dapat dikatakan mahasiswa membaca detail apa yang mereka dapat dalam media digital, itu terbukti $60 \%$ mahasiswa selalu membaca konten atau isi informasi yang diperoleh.

2. Apakah anda selalu bisa memahami isi berita yang realistis?

Apakah anda bisa membedakan berita yang anda dapatkan fiksi atau realistis?

181 responses
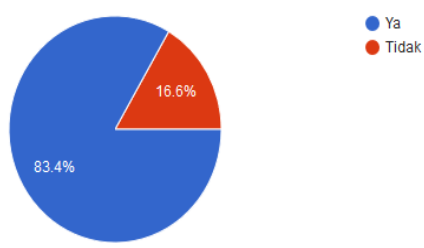

Dengan jawaban di atas maka dapat disimpulkan bahwa mahasiswa dapat membedakan mana berita yang sebenarya atau hanya isu saja. Jawaban tersebut memberikan skor $80 \%$ mahasiswa dapat memahami dengan baik. 
3. Apakah sumber rujukan dalam suatu informasi merupakan suatu yang penting dalam keakuratan informasi?

Ketika mendapatkan informasi/ berita apakah sumber/ rujukan dari berita tersebut penting?

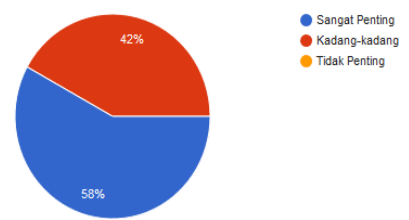

Dari paparan jawaban di atas dapat ditarik kesimpulan bahwa mahasiswa sangat perlu dan memahami dari mana sumber rujukan untuk dijadikan landasan keakuratan suatu informasi.

4. Ketika mendapatkan informasi/berita apakah anda tahu kevalidan dari sumber/ rujukannya?

Ketika mendapatkan informasi/ berita apakah anda tahu kevalidan dari sumber/ rujukannya?

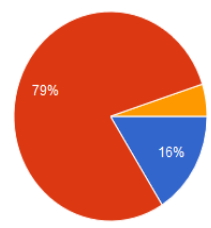

- Yatahu

kadang tahu, kadang tidak

Tidak tahu

Dari paparan jawaban di atas mahasiswa kadang tahu kadang tidak sumber rujukan berita yang sedang dibacanya.

5. Berapa jam dalam sehari rata-rata anda mengakses internet?

Berapa jam dalam sehari rata-rata anda mengakses internet?

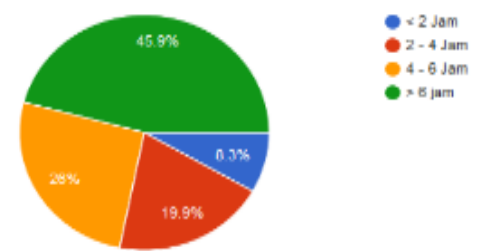

Mahasiswa rata-rata mengakses internet lebih dari 6 jam yang biasanya digunakan untuk berkomunikasi mencari informasi dan mengenalkan dirinya sendiri pada dunia luar.

6. Dalam sehari ketika anda mengakses internet media informasi apa yang sering dibuka?

Dalam sehari ketika anda mengakses internet media informasi apa yang sering anda buka? 181 responses
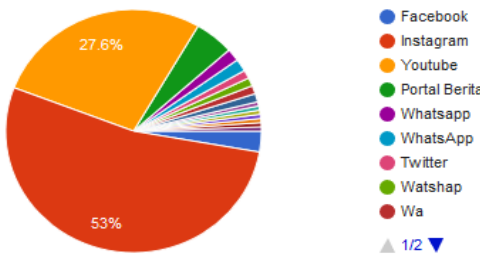

Mahasiswa lebih suka membuka instagram yang mana lebih digunakan untuk mencari informasi tentang orang lain.

7. Jika anda mencari suatu informasi di internet bagaimana anda mendapatkannya?

Jika anda mencari suatu informasi di Internet, bagaimana anda mendapatkannya?
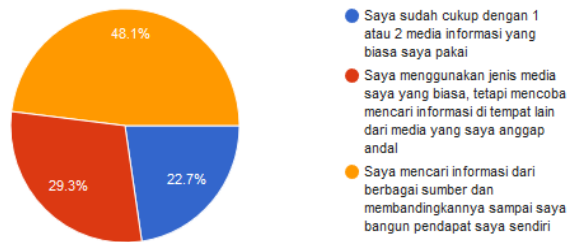

Mahasiswa untuk membuktikan keakuratan informasi dengan cara mencari informasi dari berbagai sumber dan membandingkannya sampai dapat membuat kesimpulan dengan sudut pandang sendiri. 
8. Bagaimana cara anda menfilter informasi yang diterima melalui internet?

Bagaimana cara Anda memfilter informasi yang diterima melalui media internet?
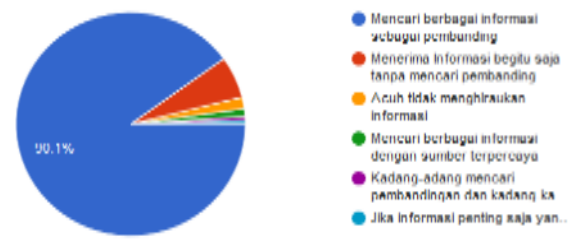

Mahasiswa mencari bermacam-macam informasi untuk menyimpulkan isi informasi yang diperoleh.

9. Jika anda mengakses suatu berita apa kalian akan mencari kebenaran dari berita yang kalian peroleh?

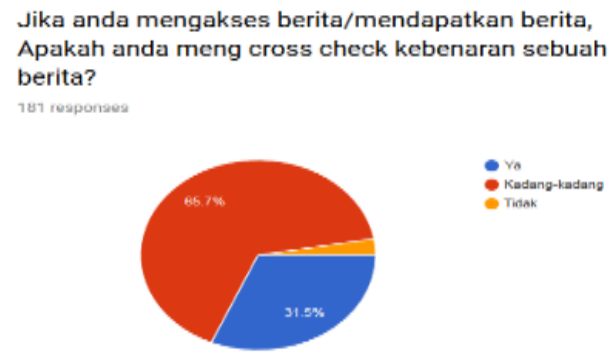

Mahasiswa hampir separuh dari jumlah 180 menjawab kadang-kadang jika ada waktu maka akan mencari kebenaran tentang berita tersebut.

10. Apa dasar anda dalam membuat penilaian tentang sebuah situs/sumber berita sebelum memasukkan data detail pribadi anda?

Apa dasar Anda dalam membuat penilaian tentang

sebuah situs/sumber berita sebelum memasukkan data detail pribadi Anda?

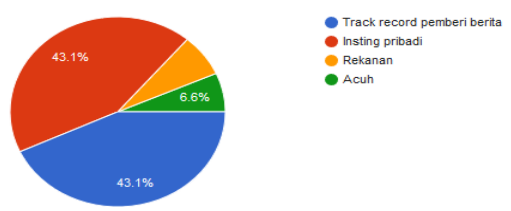

Mahasiswa membuat penilaian pada sebuah situs berita sesuai dengan kepercayaan dan sudut pandang mereka masing-masing.

Dari paparan data di atas peneliti melakukan perhitungan literasi digital yang dilakukan oleh 180 mahasiswa dengan tingkatan mahsiswa. Dari 180 mahasiswa menjawab $60 \%$ mahasiswa membaca secara detail informasi yang diperoleh dari media digital, baik dari segi judul dan isi. Mahasiwa selalu bisa memahami isi berita yang realistis dengan prosentase $80 \%$ dengan pemahaman yang cukup bagus. Mahasiswa sangat perlu memahami sumber rujukan untuk dijadikan landasan keakuratan suatu informasi hampir separuh dari jumlah mahasiswa menjawab sangat perlu. Mahasiswa rata-rata mengakses internet atau membuka media digital lebih dari 6 jam perhari hanya untuk membuka media digital saja. Mahasiswa mencari informasi rata-rata untuk mencari keakuratan informasi dari berbagai sumber kemudian membuat kesimpulan dari sudut pandang. Untuk penfilteran informasi yang di lalui melalui internet mahasiswa mencari berbagai macam informasi untuk menyimpulkan isi informasi yang diperoleh sebesar 88\% menjawab selalu berusaha mencari sumber dan data yang akurat. Mahasiswa selalu berusaha membuat penilaian pada sebuah situs berita sesuai dengan kepercayaan dan sudut pandang masing-masing

\section{Tingkat Kemamampuan Literasi Digital Mahasiswa PGSD pada Media literasi Digital}

Pernyataan tentang tingkat kemampuan literasi media dibagi tiga kategori, yaitu basic, medium, dan advanced.

1. Mahasiswa dikatakan memiliki kemampuan dalam katagori Basic, kemampuan dalam mengoperasikan 
media tidak terlalu tinggi, kemampuan dalam menganalisis konten media tidak terlalu baik dan kemampuan berkomunikasi lewat media terbatas. Nilai untuk kemampuan basic ini berada dalam score dengan range 0-14.

2. Medium, kemampuan mengoperasikan media cukup tinggi, kemampuan dalam menganalisis dan mengevaluasi konten media cukup bagus, serta aktif dalam memproduksi konten media dan berpartisipasi secara sosial. Nilai untuk kemampuan medium ini berada dalam score dengan range 15-28

Kesimpulan data yang didapatkan dari 180 reponden mahasiwa PGSD angkatan 2018 didapatkan ada yang mempunyai score dengan 0-14, score 15-28 dan Hasil scoring menunjukkan hasil sebagai berikut:

1. Responden sejumlah 60 orang atau sebanyak $33,15 \%$ berada dalam kategori Basic dalam kemampuan critical understanding

2. Responden sejumlah 114 orang atau sebanyak 62,98\% berada dalam kategori Medium dalam kemampuan critical understanding

Temuan tersebut dapat diartikan bahwa mayoritas mahasiswa dalam hal kemampuan menganalisis dan mengevaluasi konten digital media atau lebih dikenal dengan literasi digital masih dalam katagori medium.

\section{KESIMPULAN}

Berdasarkan hasil dari data yang diperoleh berkaitan literasi digital oleh mahasiswa PGSD, kesimpulan yang dapat ditarik oleh peneliti adalah sebagai berikut: (1) Mahasiswa PGSD sudah memiliki kemampuan literasi media digital terbukti mahasiswa sudah bisa menfilter berita yang baik dan kurang baik; (2) Mahasiwa melakukan litrerasi media digital lebih banyak digunakan sebagai ajang untuk menjalin relasi.

\section{Daftar Pustaka}

[1] Buchingham, D (2001) Digital Media Literacies: rethinking media education in the age of the Internet, Research in comparative and International Education.

[2] EAVI. (2009). Study on assesment criteria for media literacy levels. Brussels

[3] Gilster, P. (1997). Digital literacy. New York: John Wiley \& Sons, Inc In Martin, A., \& Madigan, D.,(Ed.). 2006. Digital literacies learning. London: Facet Publishing.

[4] Kentonon, J., Blummer, B. (2010). Promoting digital literacy skills: examples from the literature andimplications for academic librarians. Community \& Junior College Librarie.

[5] Kurnia, D, N dkk (2018) Hubungan Pemanfaatan Media Sosial Instagram Dengan Kemampuan Literasi Media UPT Perpustakaan Itenas, Edulib Vol. 8 (1)

[6] Lutviah. (2011). Pengukuran Tingkat Literasi Media Berbasis Individual Competence Framework: Studi Kasus Mahasiswa Universitas Paramadina. Skripsi Tidak diterbitkan. Jakarta: Direktorat Quality Assurance, Research and Knowledge Management, Universitas Paramadina.

[7] Martin, A., \& Grudziecki, J., (2006). DigEuLit: concepts and tools for digital literacy development.Innovation in Teaching and Learning in Information and Computer Sciences

[8] Meyers, E.M., Ingrid, E., \& Ruth, V.S. (2013). Digital literacy and informal learning environments: an introduction. Learning, Media and Technology

[9] Stefanny, S. dkk. (2017). literasi digital dan pembukaan diri: studi kolerasi penggunaan media social pada pelajar remaja di Kota Medan. Sosiglobal Vol. 2. 